\title{
Does Rhetoric Have a Place in Wohlrapp's Theory of Argument?
}

\section{KATHARINa STEVEns (née von RADZIEWSKY)}

\author{
Department of Philosophy \\ University of Lethbridge \\ 4401 University Drive \\ Lethbridge, $A B$ \\ Canada T1K 3M4 \\ katharina.stevens@uleth.ca
}

\begin{abstract}
This paper aims to determine whether rhetoric has a place in Wohlrapp's theory of argumentation. Wohlrapp's own attitude towards rhetoric is ambiguous. There are passages in his book where he grants that rhetoric might have a role to play when it comes to the subjective side of argumentation. Overall, however, he views rhetoric with deep suspicion. I argue that in spite of Wohlrapp's negative attitude, his theory of argumentation would benefit from integrating a theory of rhetoric. I take Wohlrapp's concepts of frame and insight as a starting point to make my case.
\end{abstract}

Résumé: Cet article vise à déterminer si la rhétorique a une place dans la théorie de l'argumentation de Wohlrapp. L'attitude de Wohlrapp envers la rhétorique est ambiguë. Il y a des passages dans son livre où il reconnait que la rhétorique pourrait avoir un rôle à jouer lorsqu'il s'agit de l'aspect subjectif de l'argumentation. Dans l'ensemble, cependant, il doute profondément de la valeur de la rhétorique. Je soutiens que, malgré son attitude négative, sa théorie de l'argumentation bénéficierait d'intégrer une théorie de la rhétorique. Je prends les concepts de cadre et de compréhension de Wohlrapp comme point de départ pour présenter mes arguments.

Keywords: frames, cognitive environment, rhetoric, Wohlrapp

\section{Introduction}

When a new theory of argumentation becomes available on the English-speaking market, such as has happened through the translation of Harald Wohlrapp's The Concept of Argument (Wohlrapp 2014), it is always interesting to work out how the new input will interact with the work that has otherwise been done in the field. ${ }^{1}$ This comment aims to determine whether

\footnotetext{
${ }^{1}$ I will here especially concentrate on Christopher Tindale's work for two reasons: Wohlrapp himself spends some time discussing Tindale's work, and the concepts Tindale develops seems especially well suited for being integrated into Wohlrapp's theory.
}

(C) Katharina Stevens, Informal Logic, Vol. 37, No. 3 (2017), pp. 183-210. 
rhetoric has a place in Wohlrapp's account of argumentation. His own attitude towards rhetoric is not entirely unambiguous. $\mathrm{He}$ is especially worried about rhetoric's focus on assent. An adequate theory of argumentation, so Wohlrapp holds, should offer ways to evaluate whether an argument manages to show the validity of the claim it is meant to support. But Wohlrapp's impression is that rhetorical argumentation theories concentrate mainly on the ability to gain assent from the audience. However, assent is at most an unreliable indicator of the goodness of argumentation because it can be given or denied for irrational reasons (p. 274²).

Nonetheless, there are passages in the book that suggest Wohlrapp's attitude towards rhetoric is not wholly negative. In his chapter on frame-structures he uses the concept of frames in order to integrate the influence of the arguer's subjectivity into his theory. Here he suggests that, should his theory manage to provide the conceptual tools necessary to handle the influence of subjectivity on argumentation, this might be a way to bridge "the gaps between knowledge and opinion as well as between validity-related argumentation and impact-related rhetoric" ( $\mathrm{p}$. 176). Similarly, Wohlrapp suggests that rhetoric might be used to communicate insight. Insight is the subjective side of validity, the realization that a piece of theory fits with the theory already accepted by the subject (see, e.g. Wohlrapp Précis, pp. 167 in this issue, and 2014, p. 274).

Wohlrapp points out that insight cannot be a condition for the validity of a thesis because it is purely subjective. I will argue that the communication of insight is nonetheless of basic importance to all aspects of argumentation. We do not only need to communicate insight into new theses, but also into new frames and into many of the argumentative moves we make. Therefore theoretical understanding of how we communicate insight is a necessary part of argumentation theory. Modern rhetorical argumentation theory does not have to be understood as a study of how to gain assent. Instead, it can provide the necessary theoretical tools to understand the communication of insight, just as Wohlrapp suggests it should.

Wohlrapp's theory of frames and frame problems is an especially suitable starting point for demonstrating that insight and a theory that can explain how it is communicated deserve a central place in argumentation theory. In the following, I will first describe the roles that the concept of insight and the concept of frames play in Wohlrapp's theory and establish the im-

\footnotetext{
${ }^{2}$ Unless otherwise noted, page and chapter numbers refer to The Concept of Argument.
}

(C) Katharina Stevens, Informal Logic, Vol. 37, No. 3 (2017), pp. 183-210. 
portance of insight. Then I will connect these concepts with modern rhetorical argumentation theory. I will use the example of Aldo Leopold's essay Axe in Hand to illustrate how rhetorical tools can be used to generate insight into new frames. Finally, I suggest that the dangers of rhetoric, that it can be used as a means of manipulation to gain undeserved assent from the audience, have to be addressed with an ethical criterion.

\section{Subjectivity in Wohlrapp's theory of argumentation}

\subsection{Wohlrapp's concept of insight}

As Wohlrapp explains in the Précis for this collection of commentaries, he understands argumentation as the practice by which we assess the validity of theses. (Wohlrapp Précis, pp. 162) A thesis is a new piece of theory meant to provide us with the solution to a problem that cannot be solved with our established, epistemic theory (pp. 68 f.). Theory has the purpose of orienting us in the world - to guide our practices. The entirety of those theories each of us accepts forms our orientation system, the theoretical lens through which we understand both ourselves and everything that we encounter (Chs. 1 and 3). However, we regularly come across practical problems for which our established body of theory cannot provide us with guidance. This is when our orientation system runs out and we need new theory. In arguing, we try to determine whether our new theoryculminating in a thesis - can be integrated with those parts of our orientation system that are already successful in guiding our practices (Chs. 2 and 3 ).

In argumentation, we attempt to establish a so-called thetic construction that connects our new thesis with our established theory through a number of inferential steps. However, everybody's understanding of the world is somewhat different from everybody else's. Our orientation-systems are not the same. Argumentation provides us with the ability to use another's subjectivity for testing our new theory before we take the risk of acting on it: the other's perspective and knowledge might be able to reveal problems - or solutions - that we, in our limited subjectivity, have not been able to think of. The subjectivity of the other and their view of the world comes in contact with ours. Together, we are able to access a less limited, slightly less subjective view on the problem and its possible solution.

During what Wohlrapp calls the "argumentative dialogue", the proponent, who suggests the thesis, builds up the thetic construction (Ch. 4.3). The opponent, whose function is to 
test the thetic construction, offers criticisms and objections designed to tear it down (Ch. 4.4). If a thesis can be connected with established theory through a thetic construction and if all objections can be dealt with, then the thesis can be considered thetically valid, as valid as it can be shown to be through argumentation alone. ${ }^{3}$ In this way, argumentation allows us to use to our advantage the differences in our subjectivities, the differences in our orientation-systems and the different ways we theorize about the world.

What has just been described is the objective side of validity. However, there is also a subjective side to the validity of a thesis. This is what Wohlrapp calls "insight" (Ch. 7.2). Wohlrapp offers his theory of subjectivity as a "theory for the possibility of insight" (p. 93). A person has gained insight into a thesis if she finds a place in her orientation-system where the thesis seems to fit in with other theory that she already uses to orient herself in the world. ${ }^{4}$ Insight, according to Wohlrapp, is the intellectual and emotional impression of fit, the arising of a new understanding. However, this is not the same as acceptance, because acceptance can be withheld or given for reasons other than the fit of the thesis with the surrounding accepted theory ( $\mathrm{p}$. 272).

Because insight is merely the impression of the possibility for a thesis to fit into one subject's orientation-system, it cannot be a criterion for the validity of a thesis that is supposed to offer orientation for actions in the outside world. Just because the subject perceives the thesis as fitting does not mean that the fit of the thesis can be formulated in a construction of reasons. And even if such a construction of reasons can be established, the thesis still has to be tested with the objections of another before it can be considered valid (pp. 272 ff.). Nonetheless, Wohlrapp believes that shared insight can be a sign that the thesis is worthwhile because it reduces the risk that the perception of fit might be an illusion caused by factors wholly outside the actual relationship between thesis and orientation system. Shared in-

\footnotetext{
${ }^{3}$ Wohlrapp makes a distinction between thetic and epistemic validity: Thetic validity is what we can accomplish for a thesis through argumentation. A thesis is valid if a construction of reasons has been erected that connects it to what is known, and if there are no objections that endanger the stability of this construction that cannot be dealt with. However, that a thesis is valid in this thetic way does not mean that it can be considered part of our knowledge base. For this to be possible, the thesis has to be acted upon successfully, it has to be integrated into our practices. In turn, these practices have to prove stable and successful. This is epistemic validity, and it cannot be achieved through argumentation alone (Ch. 7.1).

${ }^{4}$ See Wohlrapp's remark about a new insight as a change in a subject's orientation-system (p. 116).
} 
sight, Wohlrapp suggests, is what should actually be described as Chaïm Perelman's "meeting of the minds"-it is an indication that two people have achieved a situation in which they see a part of the world in the same way (pp. $274 \mathrm{f}$.).

Sometimes, insight comes easily and suddenly, while pondering a problem. It has the motivating effect to make the subject want to explore a new thesis further, connect it to existing theory, act according to it. And ideally, the thetic construction that connects a valid thesis to the already established theory also generates insight. ${ }^{5}$ However I would like to emphasise that insight is not guaranteed, even if a thesis can be shown to have thetic validity. ${ }^{6}$ This is so because in order for a subject to have insight into a thesis, she needs to perceive it as fitting into her orientation system. As we have already said, everybody's orientation system is different from everybody else's. None will contain all the theory we might be willing to call established knowledge, each will contain some unsustainable opinions. Even if a thesis has been shown to have thetic validity because all objections can be answered, this does not mean that everybody has an orientation system that will provide the necessary basis to support the thetic construction. That we are at a point at which we can consider certain claims of theoretical physics knowledge ${ }^{7}$ does not mean that any sixteen year-old can gain insight into these claims and connect them to their orientationsystem.

The best thing rhetoric can aim for, according to Wohlrapp, is the communication of insight. (Wohlrapp Précis, p. 167) But he is afraid that instead, rhetoric is preoccupied with assent (p. 274). I believe not only that rhetorical argumentation theory already provides tools to understand the communication of insight, but also that this role is far more important than Wohlrapp seems to acknowledge in his book and in the précis for this collection of commentaries.

\footnotetext{
${ }^{5}$ Wohlrapp's definition of argumentative validity includes a reference to this ability to create insight: "Argumentative validity is the quality of a conclusion, acknowledged in the forum, of conveying and/or consolidating, as the result of an objection-free justification, insights into a domain in question and thus suitable as a new orientation for action in this domain" (p. 270, italics in the original).

${ }^{6}$ Wohlrapp agrees (p. 275).

${ }^{7}$ Which is more than thetic validity - it is epistemic validity. An epistemically valid piece of theory, in addition to being justified and free from objections, also has a guiding function in our established practices.
}

(C) Katharina Stevens, Informal Logic, Vol. 37, No. 3 (2017), pp. 183-210. 


\subsection{Wohlrapp's concept of frames}

The differences in our orientation-systems are not only the source for the effectiveness of argumentation as a practice for testing the validity of theses. They are also the source of problems. Wohlrapp uses the concept of frames in order to describe the most intractable of these problems. This concept can be used to show most clearly how important the generation of insight is, and by extension, why rhetoric plays an important role in argumentation and why a theory of rhetoric needs to be integrated into the theory of argumentation. ${ }^{8}$

After briefly explaining Wohlrapp's concept of frames, I will distinguish two different ways in which our subjectivity challenges our ability to test the validity of theses through argumentation. One of these challenges is the fact that the ability of each arguer to help in the testing of the thetic construction is limited by their perspective on the world. Wohlrapp's argumentation theory offers techniques for managing these problems. The other challenge is that the limits of our orientation-systems limit our ability to understand each other's contributions to the building and testing of thetic constructions. Only a theory of rhetoric devoted to the exploration of ways to generate insight not only into theses, but also into frames and argumentative moves, can offer guidance here.

What frames are is most easily explained using Wohlrapp's own example of Wittgenstein's famous duck-rabbit head (p. 191). As is well known, the drawing of the duck-rabbit head (from now on: $\mathrm{H}$ ) can be seen both as a duck and as a rabbit. In order to understand the concept of a frame, imagine for a moment that you have only ever seen a rabbit when you looked at $\mathrm{H}$. Therefore, when you look at $\mathrm{H}$, you see it in the frame [as rabbit]. The frame is the $\mathrm{A}$ [as $\mathrm{B}$ ] structure that allows you to see a rabbit when you look at the lines that make up $H$ (p. 176). However, $\mathrm{H}$ can also be seen as a duck. But as long as you are not aware of the possible frame $\mathrm{H}$ [as duck] you are not aware that you are seeing $\mathrm{H}$ [as rabbit]. To you, there simply exists a picture of a rabbit, not a picture of a duck, and certainly not a picture of the duck-rabbit head. Wohlrapp calls frames that we do not know of latent frames (p. 183). If you see $\mathrm{H}$ in a latent $\mathrm{H}$

\footnotetext{
${ }^{8}$ Wohlrapp is not the only one who is interested in the concept of frames with respect to argumentation. In rhetoric, there is considerable interest in frame-shifting, which is seen as a rhetorical device (see, e.g. Zarefsky 2014, Chapters 10 and 11). However, Wohlrapp develops a concept of frames specifically designed to describe the subjective side of argumentation within his theory of argument.
}

(C) Katharina Stevens, Informal Logic, Vol. 37, No. 3 (2017), pp. 183-210. 
[as rabbit] frame, you do not know the other ways to see $\mathrm{H}$ and you do not know about your ignorance.

Of course, latent frames can become manifest. If you somehow realize that $\mathrm{H}$ can also be seen as a duck, then you become aware of the $\mathrm{H}$ [as rabbit] frame, and the rabbit becomes a rabbit-aspect (p. 183). You are now able to switch between two manifest frames or aspects of $\mathrm{H}-\mathrm{H}$ [as rabbit] and $\mathrm{H}$ [as duck]. However, by realizing the possibility of seeing $\mathrm{H}$ [as duck] you have not gotten rid of all your latent framings of $\mathrm{H}$. You now quite probably have a latent frame $\mathrm{H}$ [as duck-rabbit-head]. This frame holds together and orders the frames that are available to you for $\mathrm{H}$. In this function, it is called your primary frame of $\mathrm{H}$ (p. 184). By integrating a new frame into your understanding of $\mathrm{H}$, you changed your primary frame for $\mathrm{H}$ and thereby the way in which you constitute it - the kind of object it is in your world (p. 192).

We frame everything that we interact with in the world. Our entire orientation-system and all the theory in it is organized in various frames. Our frames also determine the kinds of inferences we are willing to make about a situation. They determine not only which claims about something we will judge to be true or false, but also which we will consider as making sense, and which will appear senseless. The claim "H's ears are too long" makes sense to you, who see $\mathrm{H}$ [as rabbit] but not to your friend, who sees $\mathrm{H}$ [as duck].

Wohlrapp explains that frames bring with them a so-called inferential potential. The inferential potential of a frame includes all those inferences that the frame allows and excludes those inferences a frame does not allow (p. 188). Through their inferential potential, frames determine the argumentative moves we can make when we build or test a thetic construction. An argument, according to Wohlrapp, connects a new thesis with our basis of established theory (pp. 73ff.). For this, it uses the inferential potential of the frame we presuppose. If you see $\mathrm{H}$ as a duck, the argument that: "These animals like water, so you should draw a pond for it" makes sense to you, even if you might reject it for other reasons. We are generally able to use all those inferences that are possible within our frame. Other inferences are, to us, not possible. We cannot form arguments that use inferences that are possible in frames that we do not know. If two arguers use different frames when referring to an object, they have available to them different inferential potentials and are able to make different arguments. If I see $\mathrm{H}$ as a rabbit, I will not form your water-pond argument. Instead, I might say: "These animals are very social, draw another one!" 


\subsection{Two kinds of frame problem}

Wohlrapp presents the problems that we encounter in argumentation due to frames as unified, but I believe that we can distinguish two different kinds of problematic effects. Wohlrapp offers a strategy for solving one kind of problem. The other is acknowledged in the book, but a solution is not explicitly integrated into his theory. This is the problem I will use as a posterchild for showing the real importance of generating insight and to introduce the necessity of a theory of rhetoric in argumentation.

On the one hand, as Wohlrapp points out in the précis to this collection of commentaries, the same argument can be better in one frame and worse in another (Précis, p.166). One frame might have the inferential potential to make a construction work, another might not. A new frame for a subject matter can completely change the status of our theory. An argumentative construction that seemed perfectly fine in an old frame can appear inadequate in a new one. ${ }^{9}$

If we discover that a subject matter can be understood in two or more different manifest frames, and that our thesis can be shown to be valid in one frame and invalid in another, then this is a problem that cannot be solved through frame-internal argumentation. If I know that there is an argumentative construction to show that $\mathrm{H}$ is a good drawing if $\mathrm{I}$ see it in the rabbit frame, and that there is an argumentative construction to show that $\mathrm{H}$ is a horrible drawing if I see it in the duck frame, then I have to do something to the frames. Wohlrapp offers solutions here. He suggests we might criticise and reject one of the frames ("When I painted it, I meant it to be a rabbit. So clearly, you cannot see it as a duck."), hierarchize the frames ("This picture could be a good rabbit or a bad duck. We are here to enjoy. So right now, we should pay more attention to it as a rabbit.), harmonize the frames ("Well, if I have to say how good it is, let's say its an A+ as a rabbit, but a $\mathrm{C}$ as a duck, and so we give it a B."), or synthesize them ("It's genius! It's a duck-rabbit-head!") (p. 261).

I would like to note that when we are at the point to argue about whether a frame is adequate, or more important than another, etc., we have opened a new argumentative dialogue in which we argue about how to deal with a difference in frames we are all equally aware of. And we deal with them within a further frame that supplies us with an inferential potential we can use. We already understand one another. In the example above, $\mathrm{H}$ was being handled once as an object under the authority of its author, once as a means for enjoyment, once as a work that

\footnotetext{
${ }^{9}$ See, e.g., the example Wohlrapp describes at pp. $202 \mathrm{ff}$.
} 
needed to be given a grade, etc., In each case there was an additional frame that provided the inferential potential to formulate arguments about how to manage the different frames for $\mathrm{H}$.

The other major problem frames can cause in argumentation brings the issue of argumentative communication into focus, because it constitutes its breakdown. This problem is that of unacknowledged frame-differences. They can come in different guises: First, we might both argue presupposing different latent frames. You might only have ever seen the duck, I might only ever have seen the rabbit, neither of us is aware of other possibilities. Second I might know of the duck-rabbit head, but you have only ever seen the duck. I know this, but you do not. Third, we might both have access to both the rabbit and the duck, but you believe we argue in the duck-frame and I believe we argue in the rabbit frame. Etc.

Here is an example: Imagine we are arguing whether your drawing, $\mathrm{H}$, is a good drawing and I tell you that H's ears are too long. Then you, who only sees $\mathrm{H}$ [as duck] do not know what I am talking about. ${ }^{10}$ This is a misunderstanding that might be easily corrected if the problem lies with a difference between frames that are manifest to both of us. If the problem lies with latent frames, we will only be able to continue our argument if we succeed in making the latent frames manifest. To each of us, the other one is uttering nonsense that we cannot understand. This is so because the way we constitute the world through our primary frames determines and limits our ability to reason. If the basic constitution we each presuppose for the part of the world that we are arguing about is different, then we cannot understand each other's inferences. We might turn away, considering the other unintelligent or malevolent. If we are lucky, we suspect a deeper issue - a latent frame issue. ${ }^{11}$ We need to make our different latent frames manifest and gain access to their inferential potentials before we can continue.

\subsection{Widening the concept of insight}

The solution to this kind of problem has to be sought beyond Wohlrapp's argumentative dialogue, which consists only of the argumentative moves the proponent and her opponent make. It carries us into what Wohlrapp calls the "communicative context

\footnotetext{
${ }^{10}$ This example is taken from Wohlrapp, who describes this problem but does not offer theory about its possible solutions (pp. $191 \mathrm{ff}$.).

${ }^{11}$ As I have argued at length elsewhere (von Radziewsky 2012), I believe that a latent frame problem is one version of what Fogelin calls a deep disagreement. (Fogelin 1985) Zarefsky, too, suggests that work on frames could be necessary to deal with deep disagreements (though he does not have Wohlrapp's concept of frame in mind) (Zarefsky 2014 Chapter 15, p.187).
}

(C) Katharina Stevens, Informal Logic, Vol. 37, No. 3 (2017), pp. 183-210. 
of the dialogue game" (p. 234). The argumentative dialogue presupposes mutual understanding for its functioning. This understanding is undermined when we encounter unacknowledged frame problems. And that makes a productive continuation of the argumentative dialogue impossible until it is re-established. Why?

Wohlrapp mostly explores argumentation as an argumentative dialogue. ${ }^{12}$ The concept of the argumentative dialogue allows him to describe the relationship between the subject and the developing thetic construction. But this relationship is not the only one that is important in argumentation. I think we should emphasize that there is also the relationship between the arguers. We need others to take the role of the opponent, to work on the construction of reasons with us, to show us where it is weak. And so we need to communicate every part of this construction to them. It is mere illustrative talk to say that the thetic construction that connects thesis and knowledge base stands between the arguers. The illustration invites an image of a house being built, with the proponent bringing stones, and the opponent knocking against them, testing the construction. This is an oversimplification. In fact, no such "between" exists. A better image is that of the proponent building a house by herself. The opponent, unable to see what she is doing, is trying to build an identical one in order to test the stability of the construction. The proponent carefully balances a new stone on what is already there, and formulates a message to the opponent, who places a stone on what he hopes is the same spot in his house. In turn, the opponent knocks against the walls of his house, and reports when things fall apart. Then the proponent can perform the same knock, and see her walls tumble down. Argumentation happens between subjects, but every subject reasons by herself. Therefore, every move in the argumentative dialogue needs to be communicated - argumentative moves and communicative context happen at the same time.

In an argumentative move, the proponent uses bits of epistemic theory and an inferential step to reach a new bit of thetic theory and integrate it in the thetic construction (pp. $73 \mathrm{ff}$.). If the opponent is supposed to test this move, she needs to understand which bits of epistemic theory were involved and how the

${ }^{12}$ I believe we could call Wohlrapp's view of argumentation as an "argumentative dialogue" the primary frame Wohlrapp uses to theorize about argumentation. This frame either excludes the frame of [argumentation as a form of communication], or marks it as unimportant or secondary. If this were correct, then this commentary could be understood as the appeal to integrate the frame [argumentation as a form of communication] into the primary frame we see argumentation in, and to integrate it as an important aspect. However, adopting this language might overcomplicate things.

(C) Katharina Stevens, Informal Logic, Vol. 37, No. 3 (2017), pp. 183-210. 
proponent plans to reach the new bit of thetic theory. This has to be communicated. But in the case of a latent frame problem this communication breaks down because proponent and opponent work with different frames that offer them different inferential potentials. For a while, this might go unnoticed. But at some point, someone tries to communicate an inference that one frame allows and the other does not. The proponent believes a certain argumentative move is obviously possible. The opponent does not even understand why it should be made at all:

"How should it eat a whole carrot with a beak?"

"What beak are you even talking about?"

Now the argumentative dialogue and its moves cannot help anymore, because we are just discovering that we are not working on the same construction. Neither of us understands what the other one is looking at. It is as if we tried to build the same house on different bits of landscape. We set the same stones on the same coordinates, but one of us was standing on flat land, while the other one was standing on a mountain. Now the results look entirely different. The only way to solve this is to go back and to try to each gain access to the other's frame. In order to do this, each of us needs to try to communicate to the other the way in which we see the world. We both need to make the other understand that our way of seeing the world, our frame, can order the other's experiences in a somewhat coherent manner. I believe that it is appropriate to extend the concept of insight in order to describe what needs to happen now and to use it not only for the subjective side of the validity of theses, but also for the subjective side of the possibility of frames and the acceptability of argumentative moves. Each of us needs to generate insight, not into a thesis, but into a frame that is new to the other. Indeed, Wohlrapp's own description of the acquisition of a new frame fits his description of insight:

Wohlrapp suggests that we have to find new frames through reflection. We are already engaged with the subject matter in our practices, otherwise we would not have come across a problem in our orientation. Therefore, we have a point of access to it that we can use when we try to find new theoretical articulations. These articulations are supposed to lead to a new or changed basic constitution for our subject matter - a new frame. However, frames cannot be accessed through inferences that use the inferential potential of other frames. Wohlrapp suggests instead that the possibility for the world to be ordered in a new frame reveals itself to me only with reference to my practices and my other established theory: I gain access to a new 
frame when its theoretical formulations illuminate my practical experience (pp. 369 ff.). Wohlrapp describes gaining access to a new frame as the sudden ability to recognize my practices and experiences through the theoretical lens of the frame. This fits his description of what it means to gain a new insight.

But how can one generate this insight? Argumentation in the form of argumentative moves that belong to a Wohlrappian argumentative dialogue is clearly out of the question: it presupposes that we already share a frame that provides the inferential potential we need. Still, an arguer who is trying to make a new frame accessible to their interlocutor needs to substantiate the claim that the subject matter can be seen from a completely different perspective. Unable to use argumentative moves, the arguer has to find other ways to make her interlocutor see the new frame. In order to do this, she needs to communicate with the goal of changing the way the interlocutor sees the world-if only for long enough that the interlocutor can access the new frame. In other words: The arguer needs to use communicative means in order to handle and modify her interlocutor's view of the world enough to generate an insight into the world as it is seen from the new frame. If she succeeds, then this is both a communicative and an argumentative achievement. She has communicated a new way to see the world, and at the same time performed a step in building her thetic construction. She has shown that there is a frame, accessible not only to her, in which she can begin to build. A frame that at least potentially delivers the inferential potential she needs for her thetic construction. ${ }^{13}$

This means that the generation of insight is not only important for theses. It is also important when it comes to the frames we use to build our thetic constructions. What about the thetic construction? Do we need to generate insight in the course of building and testing it?

I believe so. There is no such thing as gaining insight into the thesis independently from understanding how its thetic construction works. Insight into the thesis means we have gained understanding of the thetic construction. It leads away from the epistemic theory towards new theory. It does so with a new combination of epistemic theory and inferential steps. This is a

\footnotetext{
${ }^{13}$ Of course, in some sense, there is an inferential move involved: Both the arguer and the interlocutor have to accept a primary frame of the world that provides the inferential potential necessary for inferences of the kind "what is actual is possible" - the frame that you have seen the world through is a frame through which the world can be seen. It should also be remarked that the two arguers might engage in argumentation about the right place the frame should have with respect to other frames. At this point, the solutions suggested by Wohlrapp become important.
} 
combination that we have not thought of before; otherwise the thesis would not be new.

Throughout the entire building of the thetic construction, newness is generated. In order for our epistemic theory to be able to serve as the basis for our thetic construction it often has to undergo some changes (p. 73). In addition, every argumentative move makes a step away from what is familiar and old and towards what is contested and new. ${ }^{14}$ The possibility of all these new steps, new understandings, new reinterpretations is at first only there for the proponent. To her, new understanding came bit by bit as she tried to find a way to justify her new thesis. She gained insight into the first version of her thetic construction through her own reasoning. The opponent is supposed to test the thetic construction and to object in two different ways if it is flawed: Either he points out that part of the thetic construction contradicts epistemic theory. Or he points out that there is a gap - that an argumentative step the proponent makes is too big, and not sufficiently supported by other theory (pp. 214ff.). In order to be able to do this, the opponent needs to gain insight in the thetic construction at least up to the point where the objection can be made. He needs to know how he can get from his orientation system up to the point at which the flaw occurs. Otherwise he cannot claim that there is a flaw because he does not understand what the proponent is trying to do. It is the proponent's task to generate this insight through the description of her proposed thetic construction. Indeed, Wohlrapp describes the objection of the form "gap" as one that might be simply the expression that the opponent cannot gain insight into the argumentative move the proponent is trying to make. ${ }^{15}$ It follows that

${ }^{14}$ Wohlrapp describes a justificatory step as a step that takes a theoretical element and uses it as the basis from which, through an operation in the form of an inference, a new, changed theoretical element can be reached (p. 143.).

${ }^{15}$ Two remarks should be made here:

First, Wohlrapp does not say that the objection "gap" is always a sign of missing insight. Indeed, the objection is especially strong when the opponent can show that the proponent's argument is circular. Then the gap has been proven: the thesis is not adequately connected to epistemic theory. A gap can also be shown to be there - independent of insight - by showing that all ways from the established epistemic theory to the thesis are barred.

Second, Wohlrapp's description of what should happen when the objection "gap" stems from a lack of insight from the opponent sounds very much like the description of what a good arguer should do that we find in rhetorical argumentation theory (see below): "As stated, this can be an expression of a very personal shortcoming. If the justification is designed methodically, however, it should be possible to aid the opponent's understanding by bridging the gap. This means, first, that the necessary beginnings have to be either located or inserted within the opponent's orientation system. But even in that case, there will still be opponents who are unable to understand, for instance, because they are hampered by subjective influences. The propo-

(C) Katharina Stevens, Informal Logic, Vol. 37, No. 3 (2017), pp. 183-210. 
unless the opponent can understand every step that is made on the way from epistemic theory to thesis, unless he can gain insight into every new piece of theory that is generated along the way, he will object. Generating insight, and finding out why insight is missing, is then a constant, necessary part of the proponent's task while she argues.

Similarly, an opponent who believes he has found a weakness in the thetic construction that his proponent has offered needs to make the proponent realize something new. New understanding needs to be generated not only for justifications, but also for objections - especially if they involve complicated operations like the integration of an additional frame, the reinterpretation of a concept, or even a small thetic construction.

Insight into the moves of the respective partner in argumentation is what prepares one's own orientation system so that one can construct one's own contributions to the argumentative dialogue. In this sense, insight carries the argumentative dialogue. Where communication breaks down the dialogue ends. Arguers stop working on the same construction.

This leads us to the following argument: Arguing would not be necessary if our orientation systems were not limited. And it would not be useful if it did not allow us to use others' orientation systems to test our thetic constructions. Argumentation is connected to the ways in which subjectivity limits us. And one aspect of these limitations makes the mutual generation of insights necessary. Therefore, arguing must involve care for communicating each argumentative move effectively as much as care for the development of a stable construction and care for the thorough testing of that construction. I believe that this is reason enough to say that Wohlrapp's "communicative context of the dialogue game" is not secondary to argumentation at all, but an integral part of it. The importance of the communication of argumentative content for the practice of argumentation warrants integrating a theory of this communication into argumentation theory. I believe that modern theory of rhetorical argumentation delivers the tools we need to develop Wohlrapp's own theory further so that it includes a theory of argumentative communication. Wohlrapp is aware that rhetoric might be useful for this purpose. Maybe because he did not pay much attention to the importance of insight, he did not explore this possibility. This is what I now turn to.

nent would then have to criticize these subjective presuppositions or something would have to be done to resolve them - this, however, often cannot be done using arguments anymore" (p. 159).

(C) Katharina Stevens, Informal Logic, Vol. 37, No. 3 (2017), pp. 183-210. 


\section{Rhetoric}

Rhetorical argumentation theory shares Wohlrapp's focus on the subjectivity of those engaged in argumentation. However, it approaches both argumentation and subjectivity from a different perspective than Wohlrapp does in most parts of his book. ${ }^{16}$

Wohlrapp is interested in subjectivity in the process of testing the validity of theses. Therefore, he groups arguers as proponents and opponents: Because my subjectivity limits me, I cannot declare a thesis valid just because $I$ can find a line of justificatory reasoning from what $I$ believe I know about the world to the thesis. I need to test this line, and you with your subjectivity and your access to other aspects of the world, can help me in this by criticising. ${ }^{17} \mathrm{We}$ are both working with a construction of reasons that connects the thesis to a basis of knowledge and firm belief. Our subjectivity plays a role in how we develop the construction further. The construction plays a role in how we develop further.

Rhetoric is most interested in argumentation as an act of communication, an interaction between arguers. Therefore, rhetoric divides arguers into speakers and audiences. ${ }^{18} \mathrm{I}$ can see a line of reasoning from what I believe I know about the world to the thesis. But you cannot. So I need to communicate to you until you can: I need to speak, and if you want to understand, you need to listen. Later, our roles can switch, you become the arguer, and I become the audience.

Rhetoric sees the speaker as doing work on the subjectivity of the audience in order to guide them to an understanding of the arguer's thesis as acceptable. As Crosswhite puts it,

[t]he claimant understands the audience to be in need of change, so there is a conflict set up between the audience as it is and the audience as the claimant would like it to be. (...) If there were not an audience in need of changechange in knowledge, perspective, intent, sympathy, mood, awareness, any kind of change-there would be no claim, no argumentation. (Crosswhite 1996, pp. 136137.)

Accordingly, rhetorical argumentation theorists share with Wohlrapp the idea that arguments are always formulated under

\footnotetext{
${ }^{16}$ We might say: Rhetoric uses a different frame.

${ }^{17}$ See, for example, Wohlrapp's description of how argumentation starts (p. 127).

${ }^{18}$ This picture can easily be recast to fit the dialogical setting in which Wohlrapp operates by imagining arguers who are engaged in dialogue as switching back and forth between the role of the arguer and that of the audience.
} 
the influence of the subjectivity of those who argue. But more than Wohlrapp, they are interested in what Wohlrapp calls the "communicative context of the dialogue game". To Wohlrapp, who describes argumentation as an argumentative dialogue, this communicative context mostly plays a supportive role. To rhetoric, the communication of justifications and objections takes a place in the center of attention. This makes rhetorical argumentation theory ideal for describing how insights can be communicated.

\subsection{Rhetoric and the task of influencing an audience's subjectivity}

Because rhetorical argumentation theorists view argumentation as fundamentally communicative, they advocate that arguers first determine their target audience and then construct their arguments to fit this audience (e.g.. Perelman and Olbrechts Tyteca 1969, p. 19; Crosswhite 1996, pp. 136 f.; Tindale 1999 p. 85). A good rhetorical argument takes the audience from where it already is to where the arguer wants it to be. In order to be able to do this, the arguer needs to study the audience's subjectivity.

Christopher Tindale uses the concept of the cognitive environment in order to describe what it means to understand and influence an audience's subjectivity. Integrating the concept of the cognitive environment with those of the orientation system and of frames will help to determine the role rhetorical argumentation theory can play for the generation of insights in general and for dealing with frame problems specifically. ${ }^{19}$

An audience's cognitive environment does not only contain the beliefs and knowledge the audience currently has, or the facts it is currently aware of. Rather, the cognitive environment consists of all those things that the audience can perceive or infer, all those things that are, so to speak, in the audience's cognitive reach (Tindale 2015, p. 145). This includes those things the audience endorses right now, those it understands and could endorse, but also those that it would need help accessing. We can formulate this using the concept of frames: Imagine again you look at $\mathrm{H}$, seeing only the rabbit, but, given time and possibly the help of another, you would be capable of seeing the duck. Then your cognitive environment contains both duck-frame and rabbit-frame, but you have not accessed the duck-frame yet, it is not part of your primary frame of $\mathrm{H}$.

Your orientation system contains all the theory you use in order to orient yourself in the world, ordered in all the frames

${ }^{19}$ See, e.g., Tindale (1992) and (2015, p. 144ff). He adapts this concept from the one introduced by Sperber and Wilson (Sperber and Wilson 1985, p. 39).

(C) Katharina Stevens, Informal Logic, Vol. 37, No. 3 (2017), pp. 183-210. 
that are accessible to you. The cognitive environment is broader than your orientation system. With respect to any subject matter (like, for example, $\mathrm{H}$ ) it contains more than your primary frame of it: The primary frame consists of all those ways of seeing $\mathrm{H}$ that you have already accessed, ordered in a certain way. By contrast, the cognitive environment contains both your primary frame and all the frames you could access right now through your own reasoning or through the help of others. Rhetoric needs the broader concept of the cognitive environment in addition to that of frames because its interest in the subjectivity of arguers is motivated by an investigation of how to influence it. This is also the reason why the concept of the cognitive environment is more fine grained than Wohlrapp's concept of frames: The cognitive environment is not only ordered in terms of what the audience has already accessed and what it can still access, but also in terms of how present what is already accessed is. ${ }^{20}$ Presence, in rhetorical terms, is what is in the foreground of the audience's attention. Imagine, for example, that you hung $\mathrm{H}$ on the wall over your couch, and, while you know that it is the duck-rabbit head, and can see the duck if you concentrate, you have always seen the rabbit when you looked at it. In the middle of the night you hear a loud "bang"_-your spouse turns around and says: (a) "I think the duck fell down." or: (b) "I think the rabbit fell down." You might take a bit longer to understand (a) than to understand (b). This is so because the frame in which $\mathrm{H}$ appears as a rabbit is more present to you.

Presence is interesting to rhetorical argumentation theory because it is easier for audiences to understand and follow inferences and arguments that make use of that which is present than that which is less present. The creation of presence, in rhetorical terms, is used to concentrate the full attention of the reader or listener on the subject. You might have had the experience, for example, that when you read a paper in which the author first listed all the premises that their argument would be based on, you were able to anticipate the conclusion before they had even stated it. This is so because seeing all the premises together made it very easy for you to perform the same steps of reasoning the author used to get to her conclusion. By creating presence, things are brought into the foreground and to the attention of the audience (Perelman 1982, p. 35). This happens for example through the vivid descriptions of objects, activities and experiences. The reader becomes engaged in the topic that is being talked about. In the best case, this encourages her to draw her own conclusions.

${ }^{20}$ For discussions of presence, see, e.g., Perelman and Olbrechts-Tyteca (1969) and Tindale (2015).

(C) Katharina Stevens, Informal Logic, Vol. 37, No. 3 (2017), pp. 183-210. 
If this way to connect the concepts of orientation system, frames and cognitive environment works, then to understand an audience's cognitive environment with respect to the subject matter addressed by the rhetorician involves a whole lot of things: It is the same as understanding (a) what the subject's primary frame of that subject matter is, (b) which frames of the subject matter are more and less present, (c) which further frames are accessible but not yet accessed, (d) how far the subject has integrated theory available in her primary frame into her orientation system, and (e) how present this theory is. Good rhetorical argumentation alters the audience's cognitive environment through communication in such a way that the audience gains the ability see how the thesis can be reached through a justificatory construction. Depending on whether or not the primary frame of the audience already offers the inferential potential necessary, this may involve making present those bits of theory necessary for certain inferences or it may involve communication aimed at making new frames accessible. In either way, the influencing of the cognitive environment is aimed at a change in the audience's orientation system, a change that allows new theory to be integrated. In other words: just as Wohlrapp wished, it is aimed at generating insights.

By integrating the concepts of frames and cognitive environments, we can see how rhetorical argumentation theory can offer the tools necessary to deal with those frame-related problems that cannot be solved through Wohlrapp's argumentative dialogue: Rhetoric is interested in argumentation as Wohlrapp's communicative context of the dialogue game. This means that rhetoric is interested in a different host of argumentative tools than Wohlrapp is: Rhetorical argumentation theory investigates the ways in which rhetorical moves can be instruments to modify an audience's cognitive environment, the way in which it sees and thinks of subject matters. All argumentative and stylistic moves are viewed with the same interest in their ability to access minds. This includes arguments of the shape modus ponens as well as analogies and means that influence the presence of a certain idea. ${ }^{21}$

This disposition to investigate all ways in which an audience can be influenced-including those ways that make new perspectives accessible - makes rhetorical argumentation theory a good candidate for providing the theoretical means for describing how to communicate insights, even if this involves having to generate insight into a new frame. Important work in this direc-

${ }^{21}$ See, e.g., the collection of argumentative means in Perelman and Olbrechts-Tyteca (1969).

(C) Katharina Stevens, Informal Logic, Vol. 37, No. 3 (2017), pp. 183-210. 
tion has already been done with the concept of invitational rhetoric (e.g., Tindale 2004, Foss and Griffin 1995).

The idea of invitational rhetoric is that the arguer uses her knowledge of the audience's cognitive environment and her ability to communicate in order to encourage the audience to take part in the construction of those thetic constructions that will be able to help them understand why her claim might be correct. The arguer uses rhetorical means to influence the audience's cognitive environment in such a way that they themselves can then easily use its inferential potential to build a thetic construction that will connect the thesis to their understanding of the world. In other words: by giving presence to the necessary parts of the cognitive environment, the arguer carries the audience part of the way and requires them to finish the reasoning process themselves. ${ }^{22}$ This is especially effective for the communication of insights because it leaves the audience the freedom to reconstruct argumentative moves so that they can reach a new bit of theory from the basis of their own orientation system instead of having to retrace the arguer's moves exactly. The resulting view on argumentation is one in which the arguer gives the audience tasks that, if it completes them, will lead it closer and closer to an insight into the subject matter under which the arguer's claim will appear acceptable or her frame accessible. ${ }^{23}$

However, it is often most instructive to see an example of what has been described. The next section is therefore dedicated to providing much needed illustration.

\subsection{For example: Using invitational rhetoric to manage frames}

If the arguer believes that their interlocutor already has or could very easily gain access to the frame they are using, but has not yet realized which frame that is, they might try to influence their interlocutor's cognitive environment simply by drawing atten-

\footnotetext{
${ }^{22}$ The use of metaphors and analogies is an example: Understand Sam as a tropical storm, then you will see that you cannot trust him! Saying this communicates to the audience that there is a perspective on Sam which will reveal him as less than trustworthy and that this perspective can be accessed if the audience manages to restructure their understanding of Sam according to their understanding of tropical storms.

${ }^{23} \mathrm{I}$ have also argued this at length in (von Radziewksy 2012). Tindale interprets the distinction between persuasion and conviction in an interesting way that applies here and shows that modern rhetorical argumentation theory does indeed describe rhetoric as aimed at insight, against Wohlrapp's own impression (p. xlviii): While the conviction that some claim is right is a purely intellectual, theoretical acknowledging that there are reasons for accepting it, and no (strong enough) reasons against accepting it, persuasion is conviction plus insight. When we are persuaded by a claim, we are personally moved by it, it motivates us and we are willing to act on it. Rhetoric aims at persuasion (Tindale 2015, p. 30).
}

(C) Katharina Stevens, Informal Logic, Vol. 37, No. 3 (2017), pp. 183-210. 
tion to the chosen frame through presence inducing rhetorical means. This might be very easy. For example, if her argument about ethical meat consumption rests on the use of the frame animal [as moral patient], she may use a narrative about her interlocutor's dog to give presence to the fact that the interlocutor already frames (some) animals as moral patients.

More complex is the case in which the arguer realizes that her audience cannot access the frame she is using. For example, the arguer might notice that the audience cannot follow her argumentative construction at all. Then the arguer might suspect that she is using a frame that the audience cannot use, and needs to enable access to the frame before she can go on. Here, a whole host of rhetorical means might need to be used in order to make the frame as easily accessible as possible. Allow me to provide you with the analysis of an example taken from Aldo Leopold's Sand County Almanac to illustrate (Leopold 1989). ${ }^{24}$ If you have access to it, you might want to read the essay AxeIn-Hand from Aldo Leopold's Sand County Almanac first, but it is not necessary (Leopold 1989, pp. 67 ff.).

The Sand County Almanac is Aldo Leopold's famous appeal for an ethic that ascribes value not only to humans or animals, but also to the land and the biotic community as a whole. But Leopold's audience-Americans of the 1940s and 1950shas no access to a perspective on the land as a possible moral patient. Leopold's audience almost exclusively sees its relationship to the land as that of an owner to her possession. As a result Leopold's book takes on the task of making accessible a new frame for the land [as a moral patient]. In the short essay Axe-inHand Leopold uses powerful invitational rhetoric to make this frame accessible.

In a very short introductory paragraph, Leopold uses his knowledge of his audience's cognitive environment to construct an analogy between the relationship of God/humans and the relationship of humans/land. Knowing that his audience can easily access a view of God as both having power of them and responsibility towards them, he draws his audience's attention to the topos of the connection between responsibility and power, giving it presence and suggesting for the first time that this relationship might also hold when it comes to the use of human power over the land (Leopold 1989, pp. 67-68). With the topoi of responsibility and power in the centre of his audience's attention Leopold now introduces the central metaphor of this short essay:

\footnotetext{
${ }^{24}$ The book first appeared in 1949.
} 
A conservationist is one who is humbly aware that with each stroke, he is writing his signature on the face of his land. (Leopold 1989, p. 68.)

According to the well-established theory of how metaphorical reasoning works, metaphors have the effect of making those who attempt to understand them see hitherto unrecognized similarities between their source ("Lion" in "Sam is like a lion") and their target ("Sam"). In order to understand the metaphor, the mind maps the target onto the source, giving presence to those attributes of source and target that can be understood as equivalents and structuring them in a parallel manner. ${ }^{25}$ This is where the rhetorical force of metaphors comes from: It is possible for an arguer to generate insight into a new frame by using her knowledge that her audience already structures another subject matter in the way the frame she wants to teach structures the target. She uses the metaphor to give presence to the way an audience frames the source subject matter, and invite them to restructure the target subject matter accordingly.

Leopold's metaphor is rather complex and makes use of the effect of metaphors in more than one way. On the surface we see a claim about the figure of the conservationist. Unlike the people described in the short introductory paragraph, the conservationist is aware of the implications of her actions. Interestingly, Leopold describes her awareness as humbly aware. The choice of this adjective is a good example of invitational rhetoric: It is not immediately clear why the conservationist's awareness should be humble. After all, signing something is not usually a humble action. By placing the word here, Leopold gives his audience an exercise to complete: understand the metaphor in such a way that the use of 'humbly' makes sense. He has prepared his audience for the completion of this exercise by bringing the topos of responsibility and power into the foreground.

Completing Leopold's exercise will show us how the metaphor can make access to a new frame easier, a frame in which the land appears [as a moral patient]. The choice of the two sources, "signature" and "face", makes use of what Leopold can assume is already available in his audience's cognitive environment. He uses what his audience associates with those two sources in order to help them along in the movement from the frame they usually see the land in to the one he wishes to make accessible to them.

The "signature" source: The use of the word 'signature' as the source for the traces the acting human leaves on the land intensifies the perception that these traces are intimately related to

${ }^{25}$ See, e.g. Holyoak (2005), Lakoff and Johnson (1980) and Black (1962). 
the actor. Signatures are used to identify the signer: A signature is a witness that she was here and did or agreed to certain things. Signatures are also often believed to reveal certain parts of the signer's character-whole businesses have been developed around the interpretation of signatures. Signatures are thereby both part of the signer's personality and revealing about it. The metaphor Leopold uses helps his audience to understand the traces left by the human on the land in this personal and revealing way.

The "face" source: By choosing to claim that the signature is written on the face of the land, Leopold anthropomorphises the land. Having a face is an especially human characteristic. The concept of a face is loaded with associations, many of which point towards personality, individuality and moral status. The human face presents moods and feelings and is often used to evaluate character. By speaking of the face of the land, these associations are utilized to transfer some of these characteristics to the land. A land that has a face has individuality, personality, etc.

Taken together, the metaphor of the signature on the face of the land and the topoi of responsibility and awareness suggest the following picture: The actions of the human transfer the traces of her personality onto the individual personality of the land-or: the personality of the land is changed so that it now mirrors, to a certain extent, the personality of the human being. The effect is a double change in perspective. Simple actions turn into a representation of the actor's character and the object of these actions turns into a being with individuality and personality. This suggests that these actions, seemingly normatively neutral before, now have a normative weight. This is because these actions now refer to character traits (that can be good or bad) and the influencing of something with individuality (that can be justified or not). The signer (the human being) has the responsibility to show herself as good through the way she influences the land. The land appears [as a moral patient].

"Humble": Together, the two metaphors make the use of the word 'humbly' acceptable. The environmentalist, having taken the perspective above, is aware that she changes the character of the land and thereby reveals her own character. She knows that she can do this either successfully or unsuccessfully - that the traces she leaves can reveal a good or a bad character; can improve the face of the land or disfigure it. This justifies her being humble. Her actions will constitute a pattern of traces that will reveal an evaluation of her character. In the worst case she will both show herself as unworthy and disfigure the land. 
After having prepared the mind of his reader by allowing him to take the described perspective on the relationship between human and land, Leopold spends the rest of the essay with an effort to make a model-case of this relationship and the implications of the new frame land [as moral patient] present (Leopold 1989, pp. 69 ff.). Leopold achieves this by developing a narrative about his own decision-making on the question of which trees to fell on his own land. By describing his bias towards pines and against birches, he engages the reader in an exercise in evaluating the reasoning that guides his action and thereby gives him guidelines as to which reasons should be weighty and which should not. At first, he lists reasons of which the majority are selfish or egocentric: He planted the pine himself, it can be sold for more money, it will make his woodlot special in his neighbourhood. He rejects these reasons as not weighty enough and then presents the possibility that he might prefer the pine because it will become the centre of a richer plant and animal life than the birch. This reason is the most favoured.

Leopold leaves it to the reader to find a justification of his selection of the good reason, even though he certainly is in possession of it: The last reason is motivated by the idea that the land is a moral patient. But by leaving this part of the reasoning to his reader, he engages him in an exercise of exploring the implications of the new frame of the land [as moral patient]. Thereby he deepens his audience's understanding of the new frame. Leopold has achieved what the rhetorician calls 'evocation' with his audience - the audience is now thinking alongside Leopold rather than following his thoughts. ${ }^{26}$ It has been guided towards gaining access and using the inferential potential of a new frame.

Aldo Leopold's use of rhetorical means is a good example for the use of rhetoric to generate insights into new frames. Generating insight into new frames requires the performance of those steps rhetorical argumentation theory describes: First, it is necessary to understand another's cognitive environment. This includes their orientation system with its accessible frames and its accepted theory, ordered by the degree of presence they have in the other's mind. It also includes the frames not yet accessed and the theory not yet learned and the possible ways to access

\footnotetext{
${ }^{26}$ Evocation is one of three goals formulated under the headline of ethos. The concern with the rhetor's ethos is the concern with the way the rhetor presents himself and his character. If the rhetor can present himself as being in communion with his audience, the audience will be more willing to follow his reasoning because they perceive themselves as active elements in the reasoning-process (Tindale 2004, pp. 20-21).
}

(C) Katharina Stevens, Informal Logic, Vol. 37, No. 3 (2017), pp. 183-210. 
and learn them. Second, this cognitive environment needs to be modified. The theory and the frames that might be helpful in making the other understand need to be highlighted in communication so to give them the necessary presence. Connections need to be established. But all this is only the issuing of an invitation. Third, the interlocutor needs to follow the arguer, allow her to modify his cognitive environment and try to perform the tasks she lays out. The first two steps were exemplified in Aldo Leopold's essay. The third one we perform ourselves when we try to understand what he wrote.

\section{The universal audience and argumentative rhetoric}

Leopold's ability to suggest an entire new frame for the land, and to engage his audience in an exercise of reasoning within this frame, shows the power that lies in rhetoric. Unfortunately, a rhetorician who has gained the ability to influence the way her audience frames the subject matter has, in her hands, a dangerous tool that makes her capable of manipulating the audience's minds. Wohlrapp is aware of this. There are sections of The Concept of Argument in which Wohlrapp views the field of traditional rhetoric with deep suspicion. He is concerned that using rhetoric might exploit the role subjectivity plays in argumentation. The rhetorician, so the worry goes, does not treat the interlocutor as an opponent whose subjectivity is an indispensable component in the process of testing the argumentative validity of a thesis. Instead, she treats the interlocutor as an audience whose subjectivity needs to be understood only so far as to determine those communicative moves that will distract her enough from possible objections to gain her assent without having to go through the bothersome business of actually arguing. To the rhetorician, Wohlrapp suggests, subjectivity might merely be a "web of conditions that have to be taken into consideration for obtaining the desired acceptance" (p. 95). Rhetoric is primarily a tool of "persuasion" and "manipulation", instead of argumentation (p. xxxvi).

Rhetoric is needed to create insights wherever new understanding is necessary in the argumentative process. Even when no big misunderstandings stand in the way, proponent and opponent have to constantly keep in mind how the other sees the world, which parts of the thetic construction they have understood. And they have to take care to make present those parts of theory they need for their argumentative moves. Therefore, the use of rhetoric to modify the cognitive environment of the other is unavoidable. Treating the other as an audience is unavoidable.

(C) Katharina Stevens, Informal Logic, Vol. 37, No. 3 (2017), pp. 183-210. 
The danger lies not in this, but in treating the other only as an audience and in aiming at creating the illusion of validity instead of insight. Other than for example in teaching or explaining, the use of rhetoric in argumentation is distinguished by the communication of thetic content, content the validity of which the arguer cannot be sure about. The other can therefore never be simply an audience that needs to be persuaded. If rhetoric is to be used so that it helps instead of hinders the argumentative dialogue, then the interlocutor has to be treated both as an audience and as an opponent who is a representative of Wohlrapp's open forum of the arguments (the place where new arguments are being offered by the respective subjects whose orientation systems grew them) (p. 287). In other words: the interlocutor has to be treated both as someone whose subjectivity constantly has to be modified to generate insight into the moves of the speaker, and as someone who is meant to contribute to the thetic construction through objections. This distinguishes the use of rhetoric in argumentation from its use elsewhere. In this context, the difference between modification and manipulation lies not in the degree to which the cognitive environment of the interlocutor is influenced - or even in the rhetorical tools that are used to this end. Rather it lies in whether or not influence is exerted with the single goal of creating insight that will enable the interlocutor to fulfill her tasks as opponent. Manipulation, in order to work, typically has to be carried out covertly so that the manipulated person does not realize what is happening and cannot resist. Modification can be done out in the open: That the interlocutor is aware that rhetoric is being used to modify her cognitive environment takes nothing away from the insight this modification enables.

I believe that the ethical boundaries of rhetorical argumentation-having to respect every interlocutor as having the status of an opponent, not just an audience - is already contained in the measure of goodness for argumentation that has been developed by modern rhetorical argumentation theory: The demand to argue well within the context of rhetorical argumentation manifests itself as the demand to treat every audience also as the universal audience (Perelman and Olbrechts-Tyteca 1969). The discussion around the nature of the universal audience is very complex and cannot be resolved here. However, this much can be said: The universal audience contains both the arguer herself and every arguer who is willing and able to (a) understand the arguments presented, (b) evaluate the thesis, and (c) formulate an objection. Having to aim at gaining the assent of the universal audience, therefore, implies two things: The arguer has to provide arguments that are able to gain her own assent, and the ar- 
guer has to provide arguments that are composed in such a way that they are meant to be able to survive all those objections the arguer is aware of. ${ }^{27}$ This means that the demand to address every audience also as the universal audience has the effect of an ethical demand to respect every audience in its status as an opponent meant to test the stability of a construction the arguer herself believes in: An arguer succeeds in persuading the universal audience only if she succeeds in persuading herself - with all she knows and all her reasoning-abilities. At least pre-meditated, intentional deception of the own self is not possible. Even if an audience could easily be deceived - having to address the universal audience as well means having to forgo this easy way to assent. Instead, the arguer has to present a construction she believes really leads to the thesis. Further, an arguer succeeds in persuading the universal audience only of she is able to answer all objections brought to her attention. This means that she has to deal with all objections the actual audience brings forwardshe has to let them perform the tasks of an opponent.

Wohlrapp discusses the universal audience but ultimately rejects it as too vague to deliver useful conditions for validity. The problem is that the mere fact that an arguer addresses the universal audience can give no indication of whether her arguments are indeed fit to show the validity of a thesis. This is not even the case if - as Tindale suggests - the established criteria of rationality as they are known to the arguer are integrated into the concept of the universal audience. Wohlrapp remarks that these criteria and their application are expressions of the arguer's subjectivity and therefore need to be open for discussion ( $\mathrm{p}$. xlvii).

No matter how justified Wohlrapp's rejection of the universal audience as a criterion for validity is, I believe the core of the idea can still be useful. If rhetoric is to be integrated into Wohlrapp's account as the theory that describes how insight is communicated, then an additional criterion for the appropriateness of argumentative communication is needed, one that distinguishes legitimate from illegitimate uses of rhetoric. The idea of the universal audience does not have to be integrated into Wohlrapp's theory to deliver a criterion by which we can determine the validity of a thesis. Alternatively, the idea of the universal audience could be used in order to express the ethical standard of respect for the audience as an opponent. ${ }^{28}$ Translated into the

\footnotetext{
${ }^{27}$ Perelman and Olbrechts-Tyteca $(1969$, p. 44). For an extended version of this line of thought, please see (von Radziewsky and Tindale 2012, pp. 110111)

${ }^{28}$ Wohlrapp himself sees that this is work the universal audience could do when he says: "What can be assumed, however, is that the proponent who
} 
terms developed in Wohlrapp's own theory, this means: If the arguer can only produce arguments through which she addresses the universal audience alongside her target audience, then she is prevented from abusing the audience's weaknesses. This includes that she may not threaten, flatter or emotionally trick them into assenting. But it also includes that she may not abuse her knowledge of the audience's primary frames. I suggest that the universal audience could be used as a criterion for the acceptability of argumentative moves, but one that is not targeted at the inferential structures the arguer presents in her thetic construction. Rather, it could be an ethical criterion about the way an arguer has to approach the subjectivity of her audience. ${ }^{29}$

\section{References}

Black, Max. 1962. Models and metaphors. Ithaca, N.Y.: Cornell University Press.

Crosswhite, James. 1996. The rhetoric of reason, Madison, Wis.: The University Press of Wisconsin.

Fogelin, Robert. 1985. The logic of deep disagreements. Informal Logic 7(1)

Foss, Sonja and Griffin, Cindy L. 1995. Beyond persuasion: a proposal for an invitational rhetoric, Communication Monographs, 65: 2-18.

Holyoak, K. J. 2005. Analogy. in: The college handbook of thinking and reasoning. eds. K. J. Holyoak and R. G. Morrison, 117-142. Cambridge, UK: Cambridge University Press.

Lakoff, G. and Johnson, M. 1980. Metaphors we live by. Chicago: University of Chicago Press.

Leopold, Aldo. 1989. A sand county almanac, New York: Oxford University Press.

Perelman, Chaïm and Olbrechts-Tyteca, Lucy. 1969. The new rhetoric, Lanham, MD: The University Press of America.

von Radziewsky, Katharina. 2012. Pulling strings. Cogency, 4(1): 121-157.

von Radziewsky, Katharina and Tindale, Christopher. 2012. Arguments for rhetorical arguments. Cogency, 4(1): 91-119.

Sperber, Dan and Wilson, Deirdre. 1986. Relevance: Communication and cognition, Cambridge: Harvard University Press.

faces the universal audience does not attempt, so to speak, to play on the obvious idiosyncrasies of his addressee. That is at least something" (p. 297).

${ }^{29}$ I would like to stress that I do not mean to say that this is all the universal audience could do, nor that rhetorical argumentation theory is necessarily limited to describing the communication of insight. Rather, I merely had the goal to show how the accomplishments of rhetorical argumentation theory can be used to develop Wohlrapp's theory further.

(C) Katharina Stevens, Informal Logic, Vol. 37, No. 3 (2017), pp. 183-210. 
210 Katharina Stevens

Tindale, Christopher. 1992. Audiences, relevance and cognitive environments. Argumentation 6 (2): 177-188.

Tindale, Christopher. 1999. Acts of arguing, Albany, N.Y.: State University of New York Press.

Tindale, Christopher. 2004. Rhetorical argumentation, Thousand Oaks, CA: Sage Publications.

Tindale Christopher. 2015. The philosophy of argument and audience reception, Cambridge: Cambridge University Press.

Wohlrapp, Harald. 2014. The concept of argument, Dortrecht: Springer.

Wohlrapp, Harald. 2017. Précis, Informal Logic, xzxz.

Zarefsky, David. 2014. Rhetorical perspectives on argumentation: Selected essays. Cham.: Springer. 